\title{
Los sistemas de reconocimiento facial: una mirada a la luz del examen de proporcionalidad $^{1}$
}

\section{Facial Recognition Systems in Light of the Proportionality Test}

\author{
Nicolás PÉREZ TRENCH ${ }^{2}$
}

Resumen: Los sistemas de reconocimiento facial abren un nuevo paradigma en el mundo de la tecnología. Con la finalidad de garantizar la seguridad ciudadana y prevenir el delito, estos sistemas de vigilancia tienen una función muy relevante. Sin embargo, la novedad trae consigo problemáticas jurídicas que pueden generar perjuicios a los derechos y garantías de las personas. Para hacer un balance de si su aplicación se encuentra justificada o no, se hará uso del examen de proporcionalidad. En la primera parte, se introduce el sistema de reconocimiento facial. Luego, se observan las objeciones generales que esta tecnología recibe y se analizan de los intereses contrapuestos en juego. Como cierre del artículo, se aplican las categorías del examen de proporcionalidad respecto de dichos intereses para arribar a algunas conclusiones provisorias.

\footnotetext{
${ }^{1}$ Este trabajo de investigación fue llevado a cabo en el marco del Proyecto IUS 08002019 0100017 CT, "Los derechos fundamentales ante los desafíos de la era digital: Una búsqueda de soluciones para Argentina en un contexto global”, de la Facultad de Derecho de la Universidad Católica Argentina.

2 Integrante del proyecto IUS. Abogado egresado con diploma de honor y Doctorando en Ciencias Jurídicas (Universidad Católica Argentina). Adscripto en la cátedra "Taller de Análisis de Jurisprudencia” (Universidad Católica Argentina).
} 
Palabras claves: Reconocimiento facial, Derechos y garantías constitucionales, Examen de proporcionalidad, Seguridad pública, Presunción de inocencia, Derecho a la igualdad y a la no discriminación

Abstract: Facial recognition systems open a new paradigm in the world of technology. In order to guarantee citizen security and prevent crime, these surveillance systems have a very relevant function. However, the novelty brings along legal problems that can infringe fundamental rights and guarantees. To determine whether their application is justified or not, the proportionality test will be used. To that end, firstly, facial recognition systems are briefly introduced. Then, general objections that this technology receives are examined, and competing interests at stake are analyzed. Finally, the categories of the proportionality test with respect to said interests are applied to arrive at some provisional conclusions.

Keywords: Facial Recognition Systems, Fundamental Rights, Proportionality Test, Equality and non-discrimination

Recibido: 22.10.2021 Aceptado: 16.12.2021

\section{Sumario}

\section{Introducción}

2. ¿Qué son y cómo funcionan los sistemas de reconocimiento facial?

3. Algunas preocupaciones que suscitan los sistemas de reconocimiento facial desde el punto de vista de la teoría de los derechos humanos

4. Los sistemas de reconocimiento facial: un análisis jurídico

a. Reconocimiento facial y proporcionalidad

b. El interés estatal: La seguridad pública 

c. La presunción de inocencia
d. El derecho a la igualdad y a la no discriminación
e. Principio de proporcionalidad en acción

\section{Conclusión}

\section{Introducción}

Una persona desea utilizar la aplicación de su entidad bancaria en el celular para realizar alguna operación habitual. Sin embargo, al abrir dicha aplicación, ya no necesita introducir su usuario y clave; basta con que ella escanee su cara para confirmar su identidad. La persona sonríe, porque esto le supone no tener que poner sus datos cada vez que desea entrar a la aplicación. En otra parte del mundo, en un día lluvioso y con poca visibilidad, un delincuente sale corriendo de un local, al que ha robado a mano armada. No obstante, no sabe que ha sido detectado por una cámara con tecnología de reconocimiento facial incorporada, que reconoce que ya tiene antecedentes criminales, y la policía ha comenzado ya su búsqueda. Afortunadamente para el malhechor, los agentes de seguridad detienen a otra persona, que nada había tenido que ver en el incidente: su único "delito" fue tener un rostro muy similar al verdadero culpable...

Esos son apenas un par de ejemplos de la utilización de los sistemas de reconocimiento facial, que parecieran haber llegado para quedarse. Cada vez en más partes del mundo se empieza a utilizar esta tecnología, tanto en la esfera "privada" (por ejemplo, en la realización de operaciones comerciales) como en la esfera "pública”, como un refuerzo a la actividad policial, y de la que se espera que se convierta en una herramienta imprescindible para combatir de forma más eficaz al delito, cualquiera sea la forma que asuma. Sin embargo, de la mano de una tecnología novedosa, aparecen muchas problemáticas que pueden poner en peligro a los individuos, sobre todo si consideramos que los distintos Estados se encuentran entre quienes 
hacen uso de esta tecnología, y que, en algunos casos, se utiliza con propósitos lamentables.

En este trabajo, abordaré algunos dilemas jurídicos que envuelven al reconocimiento facial. En particular, centraré el foco sobre la relación de este sistema con aspectos vinculados al derecho penal y constitucional, respectivamente. Para ello, en primer lugar, haré una aproximación básica y preliminar hacia la tecnología de reconocimiento facial, su funcionamiento y las tareas en las que se la utiliza. Después, me sumergiré brevemente en las inquietudes que este sistema genera en el plano de la teoría de los derechos humanos. Mi objetivo central es realizar un análisis jurídico sobre la base del examen de proporcionalidad, para lo cual desarrollaré de manera teórica los elementos básicos involucrados en la aplicación de los sistemas de reconocimiento facial para luego aplicar los submandatos de dicho examen y, como corolario del trabajo, dejar planteadas algunas conclusiones sobre todo lo precedente.

Para finalizar esta introducción, hay que poner de manifiesto que la conclusión a la que se pueda llegar, si es que es posible, no tiene pretensiones de ser definitiva ni mucho menos; es meramente un aporte al creciente debate sobre la utilización de esta tecnología en distintas partes del mundo, debate cuyo fin aún no se vislumbra.

\section{2. ¿Qué son y cómo funcionan los sistemas de reconocimiento facial?}

El Centro de Privacidad y Tecnología de la Facultad de Derecho de la Universidad de Georgetown realizó un estudio llamado The Perpetual Line-up. Unregulated Police Face Recognition in America (Garvie et al., 2016), en el que llevó a cabo un análisis detallado de la utilización del reconocimiento facial por parte del FBI y las agencias policiales en las distintas jurisdicciones de los Estados Unidos. Allí se define esta tecnología y su funcionamiento: 
"El reconocimiento facial es el proceso automatizado de comparar dos imágenes de caras para determinar si representan al mismo individuo. Antes de que el reconocimiento facial pueda identificar a alguien, un algoritmo primero debe encontrar la cara de esa persona dentro de la foto. Esto se llama detección de rostros. Una vez detectada, una cara se "normaliza": se escala, se rota y se alinea para que cada cara que procese el algoritmo esté en la misma posición. Esto facilita la comparación de las caras. Luego, el algoritmo extrae características de la cara, características que pueden cuantificarse numéricamente, como la posición del ojo o la textura de la piel. Finalmente, el algoritmo examina pares de caras y emite una puntuación numérica que refleja la similitud de sus características. El reconocimiento facial es inherentemente probabilístico: no produce respuestas binarias de 'sí' o 'no', sino que identifica coincidencias más probables o menos probables" (Pato y Millett, 2010, como se citó en Garvie et al., 2016, p. 9).

El reconocimiento facial tiene una utilización significativa en el ámbito de la seguridad. Esto se puede ver tanto desde el ángulo de lo privado como desde lo público. En este primer aspecto, el sistema ya es utilizado por distintas aplicaciones y dispositivos, que tienen la capacidad de verificar la identidad del usuario y, de esa manera, prevenir intrusiones, ya sean accidentales o indebidas.

En el ámbito público, el sistema de reconocimiento facial es utilizado con el objetivo de determinar la identidad de las personas filmadas por las cámaras, en base a una serie de algoritmos, con un porcentaje de compatibilidad. Por lo tanto, este sistema suele ser utilizado por las agencias de seguridad, que están interesadas en capturar a delincuentes o personas sospechadas de haber cometido ilícitos. Además, se ha usado la tecnología de reconocimiento facial en 
lugares altamente concurridos, tales como aeropuertos y en espectáculos masivos, como recitales y eventos deportivos. ${ }^{3}$

El estudio reseña que la policía utiliza esta tecnología para cuatro tareas específicas principales (Garvie et al., pp. 10-12):

1. Detención e identificación: también denominada "identificación de campo", ocurre cuando el agente policial le saca una foto a una persona que se resiste a identificarse, y dicha foto es procesada mediante un software de reconocimiento facial que busca coincidencias en diversas bases de datos.

2. Arresto e identificación: en el caso de un arresto, se utiliza la foto sacada a los fines de su inclusión en la ficha policial y se incorpora a una base de datos para realizar una búsqueda interna y comparación con información previamente almacenada. Incluso se puede compartir dicha foto en una búsqueda en otras bases de datos.

3. Investigación e identificación: durante el transcurso de una investigación, se obtienen fotos o capturas congeladas de cámaras de vigilancia, y dicha información es comparada con la ya existente en bases de datos.

4. Videovigilancia en tiempo real: si la policía está buscando a una persona o a un grupo, se utilizan los circuitos de cámaras de vigilancia para realizar dicha búsqueda $\mathrm{y}$, mediante la adición previa de fotos de la/s persona/s en

\footnotetext{
${ }^{3}$ Como dato anecdótico, Sabrina Lochner reseña que la policía utilizó, sin que el público supiera, tecnología de reconocimiento facial para identificar a quienes asistían al Super Bowl XXXIV, uno de los eventos deportivos más importantes de los Estados Unidos. La American Civil Liberties Union (ACLU) expresó indignación por lo sucedido y señaló que ello podía haber constituido una violación a la Cuarta Enmienda de la Constitución de los Estados Unidos, que protege el derecho de las personas, domicilios, papeles y efectos frente a las aprehensiones y pesquisas arbitrarias. Ver Lochner S. (2013), “Saving Face: Regulating Law Enforcement's Use of Mobile Face Recognition Technology \& Iris Scans”, Arizona Law Review, volumen 55, número 1, 2013, pp. 201233.
} 
cuestión, se hace una comparación con las imágenes obtenidas en tiempo real.

\section{Algunas preocupaciones que suscitan los sistemas de reconocimiento facial desde el punto de vista de la teoría de los derechos humanos}

Cualquier consideración que hagamos sobre los desafíos que implica el sistema de reconocimiento facial no puede ser aislada, sino entendida dentro de un contexto más amplio, que es también el marco general de nuestro proyecto de investigación: los desafíos que las nuevas tecnologías le plantean al derecho. ${ }^{4}$

Volviendo al tema que aquí tratamos, ya la doctrina ha empezado a formular algunas inquietudes generadas por la irrupción del reconocimiento facial en estos últimos años. En su artículo, "El ojo blindado. Una perspectiva de derechos fundamentales sobre el uso de tecnología de reconocimiento facial por parte de fuerzas de seguridad", Eduardo Ferreyra realiza un examen crítico sobre las falencias y problemas del Sistema de Reconocimiento Facial de Prófugos (SRFP), establecido en el ámbito de la Ciudad Autónoma de Buenos Aires. Allí, Ferreyra explica que los dilemas del reconocimiento facial se dividen en aspectos sustanciales, formales y procedimentales (Ferreyra, 2020).

Dentro de los aspectos sustanciales, el autor resalta la multiplicidad de derechos que pueden verse afectados: el derecho a la privacidad, en tanto todas las personas pueden ser rastreadas a través

\footnotetext{
${ }^{4}$ En el proyecto IUS, mencionado en el primer pie de página, indagamos sobre las problemáticas generadas por la vinculación de la tecnología con el derecho, y los efectos que ello puede generar en la sociedad. Algunos de los temas abordados incluyen el ciberbullying, la protección de datos personales, el acceso a Internet como derecho humano, el abordaje de la jurisprudencia sobre libertad de expresión en Internet, entre otros.
} 
de esta tecnología; la libertad de expresión, en la medida en que las personas, al ser conscientes de que están siendo vigiladas, evitan adoptar conductas pasibles de ser sancionadas; el derecho a la igualdad y a la no discriminación, si la acción del reconocimiento facial se concentra de manera indebida o es menos eficaz respecto de determinados sectores de la sociedad y; la libertad ambulatoria de las personas, que se puede ver afectada a raíz de su identificación mediante un falso positivo con un sospechoso (Ferreyra, 2020, pp. 131-132). Estos dos derechos serán analizados con más detalle en la próxima sección.

Respecto de los aspectos formales, Ferreyra destaca la importancia de la necesidad de que el sistema cuente con elementos de análisis, transparencia y control para poder evaluar apropiadamente la efectividad del reconocimiento facial; también hace hincapié en que el sistema esté dotado de la publicidad necesaria para que la ciudadanía sepa en dónde será captada por la tecnología. Por último, es también necesaria la protección de un órgano independiente para evitar excesos (Ferreyra, 2020, p. 133).

Por último, en cuanto a los aspectos procedimentales, el autor pone de manifiesto la existencia de una tensión entre derechos y seguridad, pero que ello no se soluciona meramente con afirmar que la seguridad pública no puede avasallar derechos, especialmente cuando son fundamentales; dicha tensión puede ser resuelta en formas que revisten mayor legitimidad democrática. Como afirma Ferreyra,

"Un debate en donde todas las partes interesadas pueden participar de la discusión es más legítimo que una decisión unilateral tomada por un solo actor. Esta es la lógica subyacente al principio de legalidad, requisito ineludible para la restricción de un derecho fundamental" (Ferreyra, 2020, p. 135).

Es importante poner énfasis en el tema de las regulaciones que deben servir como marco de aplicación del reconocimiento facial. No 
basta solamente con un amplio debate y sometimiento de la cuestión al pleno de la ciudadanía y al Poder Legislativo, órgano representativo por excelencia del sistema democrático. Lo que importa es que del fruto de esta deliberación deben surgir los medios para que, en los casos en que la tecnología ya se encuentre en funcionamiento, o bien aún no haya sido introducida, existan distintas formas de controlar y auditar su uso, a fines de corregir los excesos y defectos que este posea.

Por ello, Monique Mann y Marcus Smith sostienen que “el control efectivo sobre la biometría requiere conocimientos técnicos, recursos y el poder para abogar a favor de los derechos individuales frente a las firmes demandas de proteger a la comunidad de la delincuencia y el terrorismo" (Mann \& Smith, 2017, pp. 136-137). Además, destacan que, en virtud de los distintos intereses en juego, debe haber varios niveles de regulaciones, pero que deben ser reforzadas por un organismo independiente en la cima de la pirámide: sin dicho organismo, los derechos individuales no serían protegidos de manera adecuada (Mann \& Smith, 2017, p. 137).

Como podemos observar, hay que reconocer que el gran problema con el que nos encontramos es el de la velocidad con la que avanza la tecnología, y el hecho de que el derecho siempre "corre de atrás", al intentar regular situaciones que de hecho ya pasan en la realidad. El problema consiste, en definitiva, en determinar qué soluciones puede proveer el derecho frente a los problemas surgidos de la tecnología, máxime cuando aquel tiene, al menos por el momento, posibilidades muy reducidas para anticiparse a dichos problemas. 


\section{Los sistemas de reconocimiento facial: un análisis jurídico}

\section{a. Reconocimiento facial y proporcionalidad}

De lo expresado más arriba, podemos arribar a una conclusión totalmente certera, aunque nada original: nos encontramos en un dilema fundamental, como suele suceder muy a menudo, entre el interés estatal, por un lado, y los derechos individuales de los ciudadanos, por el otro.

En este caso particular, el interés estatal se centra en la seguridad pública, parte de una esfera de competencia que pertenece tradicionalmente al Estado, el poder de policía. No viene al caso realizar aquí consideraciones sobre el poder de policía, un tema que volveremos a tratar en la siguiente subsección, y cuyos alcances han sido ampliamente discutido por la doctrina y la jurisprudencia. Sin embargo, sí señalamos que, como suele suceder en muchas otras áreas, los alcances y limitaciones de esta potestad estatal se encuentran en constante fluctuación, susceptible de ser ampliada o restringida según la necesidad del momento. ${ }^{5}$

Por el lado de los individuos, están en juego tres derechos fundamentales: en primer lugar, el derecho a la igualdad y a la no discriminación, de capital importancia en el ámbito actual del derecho internacional de los derechos humanos; en segundo lugar, la garantía de la presunción de inocencia de cada persona, dentro del marco del derecho a un debido proceso; y, por último, aunque no menos importante, el derecho a la privacidad, del cual deriva la

\footnotetext{
${ }^{5}$ El ejemplo más claro de esta afirmación puede encontrarse en la constatación de la variadísima selección de medidas tomadas por los distintos países para hacer frente a la emergencia sanitaria causada por la pandemia del coronavirus, al margen de cualquier consideración sobre si dichas medidas fueron más o menos eficaces para llevar a cabo sus cometidos.
} 
cuestión de la protección de los datos personales y que sería más provechoso analizar, con mayor extensión, en un futuro trabajo. ${ }^{6}$

Haciendo una simplificación extrema, se trata de la ya clásica tensión entre seguridad y libertad (o, si uno desea usar la terminología de Ferreyra, entre derechos y seguridad), tema que en el derecho (y en el ámbito de las ciencias sociales en general) tiene carta de ciudadanía desde antaño. Y, como cualquier avezado lector podrá darse cuenta, es un problema que no parece tener solución. Sea que uno se incline por el punto de vista del interés estatal o por el de los derechos y garantías individuales, hasta el momento no hay respuestas acabadas al dilema.

Sin embargo, aun cuando esta tensión no tenga una solución aparente, hay mecanismos que pueden ser útiles para hacer un análisis pormenorizado de la cuestión. En particular, es interesante destacar el examen de proporcionalidad, un tema abordado por el jurista alemán Robert Alexy en una de sus principales obras, Teoría de los derechos fundamentales (Alexy, 1986/1993). Este sistema, que se divide en tres submandatos, permite determinar si el avance del Estado sobre los derechos y garantías en un caso particular es justificado o no; en última instancia, el examen de proporcionalidad determinará si la medida bajo análisis es constitucional. Este método fue desarrollado por el Tribunal Constitucional Alemán (Bundesverfassungsgericht), y de allí, su uso se ha extendido a distintos tribunales en todo el mundo. Asimismo, a nivel regional es aplicado tanto por el Tribunal Europeo de Derechos Humanos como por la Corte Interamericana de Derechos Humanos, aunque con algunas variaciones, notablemente el de la incorporación de la

\footnotetext{
${ }^{6}$ En particular, habría que centrarse en la obtención de los datos biométricos, que, al ser datos personales de cada individuo (que integran el conjunto de sus derechos personalísimos, y que implica, a su vez, la participación del derecho a la privacidad), supone la obligación de una protección integral a través de la normativa pertinente. Asimismo, correspondería abordar también las dudas respecto a cómo el Estado mantiene dicha información, y si toma todos los recaudos necesarios para asegurar su destrucción una vez que el Estado no tiene justificación alguna para poseer los datos biométricos en sus bases de datos.
} 
finalidad legítima, un presupuesto previo a la aplicación de los demás submandatos. Para este trabajo, no obstante, seguiremos la formulación clásica del examen de proporcionalidad.

Conforme al examen de proporcionalidad, ante la existencia de un principio que, de ser aplicado, entra en colisión con otro principio opuesto, se busca determinar si el beneficio que se deriva de proteger al primero es superior al grado de restricción o afectación respecto del segundo. En base a ello, este método consta de tres submandatos: idoneidad, necesidad y la proporcionalidad en sentido estricto:

1. El submandato de idoneidad, también denominado de adecuación, supone que el accionar de un individuo o del Estado debe ser adecuado al fin perseguido por las limitaciones al derecho fundamental (Villaverde, 2008, pp. 183-184).

2. El submandato de necesidad requiere que dicho accionar sea necesario para lograr el fin previsto, y que además no haya algún otro medio menos oneroso y restrictivo que pueda suplirlo. Si hay elección posible entre dos medios, siempre debe aplicarse la forma menos gravosa (Villaverde, 2008, p. 184).

3. El submandato de proporcionalidad en sentido estricto se refiere al sacrificio exigido al derecho fundamental limitado por la medida o acción, y el concreto derecho, interés o bien jurídico que pretende garantizarse con ese límite. Lo que busca este submandato es que el derecho fundamental sea restringido en lo estrictamente necesario para asegurar la protección de los derechos que lo limitan. Sin embargo, dicho límite no puede excederse de lo requerido para evitar el mal mayor. Se trata, en última instancia, de que haya un equilibrio, y de que, de la mayor consideración otorgada a uno u otro principio, se deriven más beneficios que perjuicios para la sociedad (Villaverde, 2008, pp. 184-185). 
La aplicación de las máximas de proporcionalidad se basa sobre el carácter de los derechos fundamentales como principios. Alexy sostiene que los principios ordenan que algo debe ser realizado en la mayor medida posible, teniendo en cuenta las posibilidades jurídicas y fácticas; por ello, no contienen mandatos definitivos sino solo prima facie. Por contraposición, las reglas, al ordenar que se cumpla con lo que ellas disponen, realizan una determinación en el ámbito de las posibilidades jurídicas y fácticas. La diferencia entre ambas radica en que, ante un conflicto concreto entre principios opuestos, uno de ellos es soslayado frente a otro de mayor peso, mientras que la existencia de dicha circunstancia no soslaya inicialmente lo dispuesto por una regla, aún si esta sostiene al principio desplazado (Alexy, 1986/1993, pp. 99-100). El hecho de considerar a los derechos fundamentales como principios prima facie implica que, como se ha mencionado más arriba, si ellos deben ser realizados en la mayor medida posible, significa que ellos pueden ser cumplidos en grados. Ello implica, a su vez, que dichos grados pueden ser ponderados, como veremos ahora.

Respecto al último submandato, la proporcionalidad en sentido estricto se realiza sobre la base de la ponderación, cuyo fin es balancear dos o más principios que se contraponen entre sí. En tanto los derechos fundamentales son principios prima facie, y dado que deben realizarse en la mayor medida posible, la cuestión aquí es de optimización relativa a las posibilidades jurídicas; lo que se procura es impedir ciertas intervenciones que sean evitables sin costo para otros principios (Alexy, 2008, p. 15).

A los fines de la ponderación, se sigue lo que se denomina como "ley de la ponderación", que dice que "cuando mayor sea el grado de no satisfacción o restricción de uno de los principios, tanto mayor deberá ser el grado de la importancia de la satisfacción del otro. Así, la ponderación se divide en tres etapas:

1. En la primera, se define el grado de afectación o de no satisfacción de uno de los principios; 
2. Luego, se define el grado de satisfacción del principio que se le opone, y;

3. Finalmente, se determina si la importancia de la satisfacción del principio justifica el grado de afectación o de no satisfacción del otro (Alexy, 2008, pp. 15-16).

A estos fines, se propone el uso de una escala triádica que define el nivel de afectación o satisfacción de los principios en leve, moderada o grave, al menos en su escala básica. Finalmente, se hace uso de la llamada "fórmula de peso", en la que se transforman los valores de la escala triádica a través de series matemáticas (Alexy admite que se pueden usar tanto la serie aritmética como la geométrica) en pesos concretos, respecto de los cuales se busca un cociente: por ejemplo, y si usamos la serie geométrica, si el cociente es superior a 1, entonces el grado de afectación del primer principio no justifica la importancia de la satisfacción del segundo. Si el cociente es inferior a 1 , el segundo principio se ve avalado en su satisfacción. Por último, si el cociente es de 1, hay un equilibrio entre ambos principios.

Ahora bien, hay que hacer algunas aclaraciones: la aplicación del examen de proporcionalidad debe hacerse siempre sobre la base de casos concretos, cosa que no ocurre en el presente trabajo, en donde solo se indaga desde una perspectiva meramente teórica. Además, hay una multiplicidad de cuestiones relativas a temas como la consideración del peso relativo que pueden adoptar los sistemas de derechos dentro del esquema de la fórmula; el mayor o menor grado de ponderación según se adopte el ángulo de los individuos que reclaman por sus derechos o el del Estado, que a veces puede adoptar sus propios intereses; la cuestión de si el mayor o menor grado del balanceo debe ser función de los jueces, o si eso interfiere dentro del ámbito de competencias del legislador. Estos temas son tratados con extensión en la obra The Constitutional Structure of Proportionality (Klatt \& Meister, 2012), y que, por razones de brevedad, dejaré de lado. 
Sin embargo, y pese a los límites señalados, es interesante intentar una aproximación a esta metodología, en la medida en que el examen es independiente al contenido del catálogo de derechos de cada país (Klatt \& Meister, 2012, p. 7). Por ende, podemos intentar hacer un esbozo del examen tomando sus elementos, aunque no sea una aplicación exacta. Para ello, primero se verán los tres aspectos en pugna que he adoptado a los fines de este trabajo: la seguridad pública como interés que el Estado desea proteger, por un lado, y la presunción de inocencia y el derecho a la igualdad y a la no discriminación como derechos que la ciudadanía ven afectados, por el otro. En base a ello, aplicaremos en la conclusión las categorías del examen de proporcionalidad para llegar a un veredicto provisorio. En este examen, prescindiré de expresar el tercer submandato utilizando la fórmula del peso.

\section{b. El interés estatal: La seguridad pública}

Es bien sabido que el ser humano es sociable por naturaleza, y que dicha sociabilidad le lleva a agruparse junto a otros seres humanos en comunidades, a fin de poder paliar sus necesidades y, de esa forma, vivir una vida lo más perfecta posible. Dicha asociación supone que, dada la múltiple y variada contraposición de intereses entre los individuos, estos decidan respetar y obedecer una serie de pautas que ordenan la vida en comunidad.

Es deber principal del Estado el asegurar las condiciones mínimas e indispensables para que haya armonía dentro de las distintas comunidades políticas. Por ello, el Estado cuenta con el monopolio de la fuerza pública como elemento coactivo para restablecer la paz social cuando esta se ve quebrantada. Dentro de este concepto, se encuentran comprendidas dos tipos de organizaciones: las fuerzas armadas, que actúan contra amenazas provenientes del exterior y las fuerzas de seguridad, para cuando el orden público es vulnerado desde el interior. Y es respecto a las segundas en donde entra en juego la idea de "seguridad pública". 
Para utilizar una definición plasmada en una normativa vigente, tomemos el ejemplo de la ley 5688 de la Ciudad Autónoma de Buenos Aires, que establece el llamado Sistema Integral de Seguridad Pública en el distrito. Su artículo segundo define el concepto de seguridad pública como:

"la situación de hecho basada en el derecho en la cual se encuentran resguardadas la libertad, la vida y el patrimonio de los habitantes, sus derechos y garantías y la plena vigencia de las instituciones del sistema representativo, republicano y federal que establecen la Constitución Nacional y la Constitución de la Ciudad de Buenos Aires"?

Sobre esta base, se entiende que la seguridad pública es el elemento sobre el cual el Estado vertebra la acción coordinada de las fuerzas de seguridad y organismos vinculados a ellas, a fin de mantener el orden interno y proteger los derechos y garantías de todos sus habitantes.

A su vez, la citada norma expresa en su artículo $7^{\circ}$, los objetivos del llamado Sistema Integral de Seguridad Pública. Entre ellos figuran:

- "Facilitar las condiciones que posibiliten el pleno ejercicio de las libertades, derechos y garantías constitucionales en la Ciudad Autónoma de Buenos Aires" (inciso a).

- "Mantener el orden y la tranquilidad pública en todo el territorio de la Ciudad..." (inciso b)

- "Proteger la integridad física de las personas, así como sus derechos y bienes" (inciso c).

\footnotetext{
${ }^{7}$ Esta definición está tomada casi en su totalidad de la Ley 24.059 de Seguridad Interior, sancionada a nivel nacional, con la sola salvedad de que la definición de la ley nacional hace mención del término "seguridad interior" y la Ley 5688, que viene a reemplazar a la anterior Ley 2894 (o Ley de Seguridad Pública, sancionada en 2008) agrega la referencia a la constitución local. De todas maneras, esta normativa expresa, en su artículo 14, que adhiere a la Ley 24.059.
} 
En la cuestión específica que aquí se trata, el sistema de reconocimiento facial funciona como una herramienta de investigación del delito, en la medida que provee a las fuerzas policiales de información que puede ayudar a la captura del presunto criminal; a su vez, es también un elemento que, desde esta óptica, contribuye a la prevención de futuros ilícitos. Además, cabe esperarse que los efectos de esta tecnología puedan contribuir a la formulación de una política criminal más eficiente para la realización de sus objetivos.

¿Y cuál es el último fundamento de la seguridad pública? En el orden del derecho constitucional y del derecho administrativo, estrechamente vinculado con aquel, la noción de seguridad pública pertenece al ya clásico tópico del poder de policía que, como expresara el juez Barbour en New York v. Miln (1837), consiste en: “(...) no solo el derecho sino la carga y obligación solemne del estado promover la seguridad, felicidad y propiedad de su pueblo y proveer su bienestar general..." (Legarre, 2004, p. 113). Dicho de otro modo, el poder de policía es esa reserva de competencia que tiene el Estado en donde ejerce sus facultades para asegurar el bienestar de los ciudadanos. $^{8}$

Ahora bien, el poder de policía no es absoluto. En primer lugar, el Estado debe cuidar que sus restricciones sean razonables y que no atenten contra los derechos y garantías de sus ciudadanos. Ante situaciones de emergencia, aquellas pueden tener un grado más intensivo, pero, a su vez, deben estar reguladas de manera aún más estricta, y deben tener un plazo determinado de vigencia en el tiempo. Y, en lo que respecta específicamente a la seguridad pública, entran también en juego los preceptos propios del derecho penal, como el

\footnotetext{
${ }^{8}$ Es una cuestión harto discutida en la doctrina (y que aquí no es pertinente tratar) si el poder de policía solamente comprende las cuestiones atinentes a la seguridad, salubridad y moralidad públicas (concepto estrecho o narrow), o si, por el contrario, es también abarcativo del interés y bienestar general (concepto amplio o broad and plenary). La jurisprudencia también ha adoptado distintos caminos, tanto en los Estados Unidos como en la Argentina, inclinándose por uno u otro criterio.
} 
principio de legalidad, según el cual no puede haber delito ni pena sin ley previa, sancionada de conformidad con los mecanismos constitucionalmente establecidos.

En particular, es interesante reseñar que el artículo $4^{\circ}$ de la ley 5688 de la CABA, en línea con lo mencionado precedentemente, establece un marco de lineamientos mínimos dentro de los cuales el sistema de seguridad pública porteño debe enmarcarse, en tanto dispone que:

"La seguridad pública es deber propio e irrenunciable del Estado de la Ciudad Autónoma de Buenos Aires, que debe arbitrar los medios para salvaguardar la libertad, la integridad y derechos de las personas, así como preservar el orden público, implementando políticas públicas tendientes a asegurar la convivencia y fortalecer la cohesión social, dentro del estado de derecho, posibilitando el goce y pleno ejercicio, por parte de las personas, de las libertades, derechos y garantías constitucionalmente consagrados".

Cabe también recordar que, ante la existencia de categorías consideradas "sospechosas", ya no basta con que el Estado acredite que su acción o la norma sancionadas persiguen un fin objetivamente legítimo. Este debe, además, demostrar necesariamente la relación de proporcionalidad entre los medios elegidos para el fin buscado, y que dichos medios deben ser aptos para causar la menor cantidad de restricciones posibles a los individuos.

Y tampoco hay que olvidarnos del fenómeno del reconocimiento del carácter constitucional de los derechos humanos, presente en nuestro ámbito con mayor vigor a partir de la reforma de 1994. En ese sentido, los individuos poseen herramientas adicionales para reclamar por las violaciones que el Estado pueda cometer a sus derechos y libertades, a través del recurso a tribunales de justicia regionales, como la Corte Interamericana de Derechos Humanos y el Tribunal Europeo de Derechos Humanos. 


\section{c. La presunción de inocencia}

La presunción de inocencia es uno de los mayores aportes del derecho penal liberal, y constituye una de las salvaguardas más importantes frente al poder punitivo del Estado. Este principio puede resumirse sintéticamente en la ya celebérrima frase "toda persona es inocente hasta que se demuestre lo contrario”. ¿Qué implica la presunción de inocencia? Dicho de manera inversa a la formulación en la oración precedente, ninguna persona podrá ser declarada culpable, hasta tanto no se dicte sentencia definitiva en donde se acredite su responsabilidad en los hechos que se le atribuyen.

La presunción de inocencia no opera de manera aislada, sino que se concatena con otros principios dentro del proceso penal. Por lo tanto, aquella opera en la medida en que se respeten las garantías del debido proceso: entre aquellas garantías contempladas por nuestra Constitución, se encuentran los principios de legalidad y de ley previa (es decir, que los procesos estén fundados en violaciones objetivas a la ley, y que ella antecede a la comisión del hecho reprobado), la del juez natural (que impide que el imputado sea juzgado por un juez distinto al que posea la competencia para ello, establecida previa al hecho perseguido), la inviolabilidad de la defensa en juicio (que al imputado no se le impida ejercer su defensa en modo efectivo) y la prohibición de declarar en contra (es decir, que el imputado no puede ser obligado a autoincriminarse) y de ser arrestado mediante orden fundada de autoridad competente (es decir, cumpliendo con las formalidades de la ley procesal).

Esto supone, naturalmente, que, si la apreciación judicial de las pruebas recolectadas en el caso no logra precisar, con el mayor grado de certeza posible, la participación del imputado en los hechos delictivos que se le atribuyen, por aplicación del principio de la duda razonable (in dubio pro reo), el juez debe pronunciar un veredicto absolutorio.

Como se ha dicho antes, la presunción de inocencia es uno de los principios centrales que vertebran la realización del proceso penal, y 
su formulación se encuentra en los más importantes instrumentos internacionales, como el artículo 11.1 de la Declaración Universal de los Derechos Humanos ${ }^{9}$, el artículo 6.2 de la Convención Europea de Derechos Humanos ${ }^{10}$ y en la primera parte del artículo 8.2 de la Convención Americana de Derechos Humanos ${ }^{11}$.

En el ámbito local, la Constitución Nacional contempla la presunción de inocencia, aunque implícitamente, en su artículo $18^{12}$. Además, los tratados internacionales señalados en el párrafo anterior han sido incorporados a nuestra legislación con jerarquía constitucional, de conformidad con el artículo 75, inciso 22. Por último, el Código Procesal Penal de la Nación sí contempla a la presunción de inocencia junto con otras garantías procesales en su artículo $1^{\circ} 13$.

Es interesante señalar que la interpretación de la presunción de inocencia varía según nos encontremos en un sistema civilista o en el common law. Como reseña Coccoli, en el common law, la presunción de inocencia opera como una regla de evidencia en sí misma y una guía para las decisiones futuras, mientras que en los sistemas civilistas (como ocurre con el argentino), la presunción de inocencia, aunque

\footnotetext{
${ }_{9}^{9}$ Artículo 11.1: "Toda persona acusada de delito tiene derecho a que se presuma su inocencia mientras no se pruebe su culpabilidad, conforme a la ley y en juicio público en el que se le hayan asegurado todas las garantías necesarias para su defensa". (Destacado agregado)

${ }^{10}$ Artículo 6.2: “Toda persona acusada de una infracción se presume inocente hasta que su culpabilidad haya sido legalmente declarada.

${ }^{11}$ Artículo 8.2: "Toda persona inculpada de delito tiene derecho a que se presuma su inocencia mientras no se establezca legalmente su culpabilidad”.

12 Artículo 18: "Ningún habitante de la Nación puede ser penado sin juicio previo fundado en ley anterior al hecho del proceso (...) Es inviolable la defensa en juicio de la persona y de los derechos". Es decir, la presunción de inocencia se sustanciará en la medida en que se observen las garantías del debido proceso y de la defensa en juicio. ${ }^{13}$ Artículo $1^{\circ}$ : "Nadie podrá ser juzgado por otros jueces que los designados de acuerdo con la Constitución y competentes según sus leyes reglamentarias, ni penado sin juicio previo fundado en ley anterior al hecho del proceso y sustanciado conforme a las disposiciones de esta ley, ni considerado culpable mientras una sentencia firme no desvirtúe la presunción de inocencia de que todo imputado goza, ni perseguido penalmente más de una vez por el mismo hecho". (Destacado agregado)
} 
constituya uno de los cimientos del proceso penal, corre por un carril separado al de las cuestiones probatorias (Coccoli, 2017, p. 232).

Como bien lo señala el término, la presunción de inocencia, aunque un principio importantísimo, no deja de ser una presunción: se trata, en este caso, de una presunción iuris tantum y, por ende, puede ser desbaratada mediante las pruebas introducidas en contra del acusado. En estas circunstancias, no es obligación del imputado defender su inocencia (pues la presunción lo cubre a lo largo del proceso, aunque en manera decreciente, a medida que este sigue su curso), sino que es la del Estado, en cabeza del fiscal, la de presentar las evidencias que demuestren la responsabilidad del imputado más allá de toda duda razonable.

$\mathrm{Y}$ aquí es donde se pueden empezar a vislumbrar potenciales problemas. Como quedará demostrado en subsecuentes ejemplos, el reconocimiento facial es capaz de cometer errores en base a falsos positivos; en base a ello, un observador podría inferir de manera razonable que hay un deterioro respecto a la protección brindada por la presunción de inocencia. En el contexto de un proceso criminal, el Estado estaría persuadido de que la identificación biométrica del imputado es precisa, o al menos razonablemente precisa. Por lo tanto, la carga de la prueba pasará ahora al imputado, quien tiene el deber (y la necesidad, por otro lado) de probar que dicha identificación está errada.

Feldstein argumenta que una de las causas de las discrepancias entre las distintas pruebas del sistema de reconocimiento facial es que pueden tener buenos resultados bajo condiciones ideales, pero que, a medida que se introducen variables inesperadas, dicha performance se resentirá y empezará a generar altas tasas de falsos positivos (Feldstein, 2019, p. 19).

Así, Coccoli argumenta, citando a Galetta, que las herramientas modernas de vigilancia tienen dos consecuencias negativas sobre la presunción de inocencia: la primera, como ya se ha mencionado, es la inversión de la carga de la prueba hacia el acusado, lo que eleva el 
umbral que este debe alcanzar para probar su inocencia y alcanzar un veredicto absolutorio. La segunda, es que este tipo de herramientas llevan a la estigmatización, en la medida en que se cree que la persona vinculada al proceso debería ser necesariamente considerada como sospechosa (Galetta, 2013, como se citó en Coccoli, 2017, p. 233).

Una muestra de lo dicho es la realización de un estudio sobre una serie de pruebas del sistema de reconocimiento facial en Londres, realizado por el profesor Pete Fussey y el Dr. Daragh Murray, del Centro de Derechos Humanos de la Universidad de Essex. Dicho estudio revela que, según los resultados obtenidos, el sistema funcionó correctamente solo en 8 casos sobre un total de 42 analizados por los especialistas. ${ }^{14}$ Ello supone un nivel de eficacia de apenas 19\%, o bien, que el sistema falló en un $81 \%$ de los casos.

Otro ejemplo que se puede mencionar es el de la propia Ciudad Autónoma de Buenos Aires, en donde, como ya vimos antes, a mediados de 2019 se implementó el Sistema de Reconocimiento Facial de Prófugos (SFRP). A dos meses de su entrada en vigencia, el Gobierno de la Ciudad de Buenos Aires había informado que el 83\% de los detenidos a través de este sistema había sido excarcelado por orden de las autoridades judiciales: en muchos casos, los jueces desistieron porque las causas eran ya viejas, y por lo tanto prescriptas. Además de ello, un $4 \%$ de las personas fueron detenidas por error, ya que no se había actualizado la información de la base de datos de la Consulta Nacional de Rebeldías y Capturas, vinculada al SFRP (Clarín, 2019).

En este orden de ideas, ¿es posible justificar el riesgo de una violación a las garantías individuales de los ciudadanos en una mayor capacidad para atrapar a presuntos delincuentes o prevenir delitos

14 Los resultados completos del estudio pueden ser consultados en https://www.essex.ac.uk/news/2019/07/03/met-police-live-facial-recognition-trialconcerns. (Recuperado el 24/12/2021) Los investigadores señalaron que tuvieron acceso a las últimas 6 pruebas (de un total de 10) realizadas por la Policía Metropolitana de Londres entre junio de 2018 y febrero de 2019. 
futuros? Según el estado actual de las cosas, el reconocimiento facial no tiene todavía la suficiente confiabilidad como para convertirse en una herramienta orientada a la vigilancia y a la seguridad. Así, por un lado, la presunción de inocencia se ve controvertida en base a los posibles falsos positivos que se puedan obtener.

Pero, por otro lado, las pruebas discordantes de los distintos sistemas podrían ser alegados como evidencia de que el sistema pudo haber tenido un error. Sobre esa base, el juez podría determinar que dicha evidencia no tiene suficiente mérito y, en consecuencia, excluirla de su consideración. Y, continuando con la hipótesis, si la identificación por reconocimiento facial era una prueba clave en el marco del proceso penal, el juez podría no tener más remedio que declarar un veredicto absolutorio; incluso el proceso podría desestimarse, si todavía no se llegó a la etapa de juicio.

Es decir, el reconocimiento facial conlleva la posibilidad de vulnerar la presunción de inocencia -o lo que es incluso peor: puede llegar a invertirla y transformarla en una carga que el imputado debe probar. Y sobre esa premisa, habría argumentos fácticos para excluir la evidencia obtenida a través de ese medio del conjunto de pruebas analizado por el juez. De ese modo, la utilización de la tecnología no solo presenta el dilema de las violaciones a las garantías constitucionales, sino que a la vez se podría tornar en un instrumento ineficiente para cumplir con sus cometidos en materia de seguridad.

Y hay asimismo un aspecto que no puede pasar inadvertido: definitivamente se necesita una mayor regulación, para resolver interrogantes acerca de la recolección y almacenamiento de la información obtenida a través del reconocimiento facial, de su utilización dentro del proceso penal, si se le atribuye un valor probatorio específico o si tiene igual peso que el resto de las pruebas convencionales, qué sucede con la información almacenada si se determina la inocencia del imputado o se desestima el caso en su contra, entre otros. 
En definitiva, al menos en el aspecto penal y su vinculación con políticas de seguridad pública, la utilización del reconocimiento facial aún deja más dudas que certezas. Si se desea usar esta tecnología, también es necesaria la acción del legislador para prevenir lamentables, y ciertamente posibles, violaciones de derechos y garantías fundamentales.

\section{d. El derecho a la igualdad y a la no discriminación}

Hay un aspecto que es imposible soslayar, y que también puede inferirse a partir de lo desarrollado hasta ahora: los softwares de reconocimiento facial pueden tener (y de hecho tienen) problemas cuando se trata de la identificación de personas pertenecientes a las minorías, una práctica que va en contra de la igualdad ante la ley y que puede violar la dignidad de las personas.

En las últimas décadas ha habido un crecimiento exponencial en el desarrollo, alcance y protección brindado por el derecho a la igualdad y a la no discriminación, que se ha generalizado a partir de su inclusión en instrumentos internacionales de derechos humanos, su interpretación por los más variados tribunales en todo el mundo y en todos los niveles, y por la aplicación práctica y normativa realizada en los distintos países. 
Basta con recordar, para dar unos ejemplos, los artículos $2^{15}$ y $7^{16}$ de la Declaración Universal de Derechos Humanos y los artículos $1.1^{17}$ y $24^{18}$ de la Convención Americana de Derechos Humanos, entre otros. En el caso particular de la Argentina, tenemos el artículo 16 de la Constitución Nacional ${ }^{19}$ y, en un plano complementario, la ley 23.592, que en su artículo $1^{\circ}$ protege a las personas contra "quien arbitrariamente impida, obstruya, restrinja o de algún modo menoscabe el pleno ejercicio sobre bases igualitarias de los derechos y garantías fundamentales reconocidos en la Constitución Nacional”.

¿Qué problemas presenta el reconocimiento facial desde la óptica del derecho aquí analizado? Recorramos ahora algunos ejemplos.

En el año 2018, la ACLU (American Civil Liberties Union) realizó pruebas con un software de reconocimiento facial desarrollado por

\footnotetext{
${ }^{15}$ Artículo 2: “Toda persona tiene todos los derechos y libertades proclamados en esta Declaración, sin distinción alguna de raza, color, sexo, idioma, religión, opinión política o de cualquier otra índole, origen nacional o social, posición económica, nacimiento o cualquier otra condición. Además, no se hará distinción alguna fundada en la condición política, jurídica o internacional del país o territorio de cuya jurisdicción dependa una persona, tanto si se trata de un país independiente, como de un territorio bajo administración fiduciaria, no autónomo o sometido a cualquier otra limitación de soberanía”.

${ }^{16}$ Artículo 7: “Todos son iguales ante la ley y tienen, sin distinción, derecho a igual protección de la ley. Todos tienen derecho a igual protección contra toda discriminación que infrinja esta Declaración y contra toda provocación a tal discriminación".

${ }^{17}$ Artículo 1.1: “Los Estados Partes en esta Convención se comprometen a respetar los derechos y libertades reconocidos en ella y a garantizar su libre y pleno ejercicio a toda persona que esté sujeta a su jurisdicción, sin discriminación alguna por motivos de raza, color, sexo, idioma, religión, opiniones políticas o de cualquier otra índole, origen nacional o social, posición económica, nacimiento o cualquier otra condición social'. (Destacado agregado)

18 Artículo 24: "Todas las personas son iguales ante la ley. En consecuencia, tienen derecho, sin discriminación, a igual protección de la ley”.

19 Artículo 16: "La Nación Argentina no admite prerrogativas de sangre, ni de nacimiento: no hay en ella fueros personales ni títulos de nobleza. Todos sus habitantes son iguales ante la ley, y admisibles en los empleos sin otra condición que la idoneidad. La igualdad es la base del impuesto y de las cargas públicas”.
} 
Amazon llamado Rekognition. Dicho sistema, que escaneó fotos de miembros del congreso federal, vinculó a 28 de ellos con una base de datos que comprendía 25.000 fotos policiales de personas arrestadas. Según la ACLU, el sistema identificó a una cantidad desproporcionada de personas de color: el $40 \%$ de los falsos positivos, aun cuando dicho segmento constituye apenas un $20 \%$ de los miembros del congreso estadounidense. Entre los falsos positivos, se identificaron a 6 miembros del Congressional Black Caucus, un grupo bipartidista que reúne a miembros del Congreso de los Estados Unidos; entre ellos se encontraba el recientemente fallecido John Lewis, congresista federal del quinto distrito del estado de Georgia y un pionero de la lucha por los derechos civiles de los afroamericanos en Estados Unidos en la década del 60 (ACLU, 2018).

$\mathrm{Al}$ año siguiente, la filial de la ACLU en California del Norte hizo otra prueba con el mismo sistema desarrollado por Amazon, utilizando la base de datos existente. En este caso, utilizaron las fotos de legisladores estatales de California: los resultados arrojaron a 26 legisladores que fueron falsamente identificados como delincuentes (ACLU of Northern California, 2019).

Aún más preocupante es la utilización del reconocimiento facial en China. Los ciudadanos chinos lo utilizan para realizar transacciones comerciales a diario. Y el gobierno chino le encuentra aplicaciones mucho más extendidas que en los otros países: recientemente ha obligado a todos los usuarios de celulares a utilizar el reconocimiento facial para su identificación (BBC News Mundo, 2019). Además de que tiene una vastísima red de 170 millones de cámaras con la tecnología incorporada para vigilancia, hay cada vez más denuncias de que el gobierno chino estaría utilizando el reconocimiento facial para internar a los uigures, una minoría étnica predominantemente musulmana, en "campos de reeducación” (BBC News Mundo, 2018), lo que ha generado rechazo en varios países de la comunidad internacional. 
A contramano de estos hallazgos, el U.S. National Institute for Standards and Technology (NIST) realizó una serie de pruebas entre 2014 y 2018 utilizando 127 algoritmos desarrollados por 39 compañías mostró que el sistema de reconocimiento facial tuvo un resultado 20 veces mejor al buscar en una base de datos para encontrar fotografías concordantes. La tasa de errores también bajó del $4 \%$ al $0,2 \% .^{20}$

Sin embargo, un nuevo estudio realizado por el NIST en $2019,{ }^{21}$ en el que fueron probados 189 algoritmos de software de 99 desarrolladores, reveló algunos resultados discordantes:

1. Para la identificación "uno a uno" (one-to-one matching, es decir, la verificación de una foto de un individuo con una foto distinta del mismo individuo) hubo altas tasas de falsos positivos entre los asiáticos y los afroamericanos. Entre los algoritmos desarrollados por los estadounidenses, el estudio arrojó tasas similares de falsos positivos en identificación uno a uno para asiáticos, afroamericanos y grupos nativos. La excepción, según el informe, está en los algoritmos desarrollados por compañías asiáticas, cuya tasa de falsos positivos en la vinculación entre asiáticos y caucásicos no es tan abultada como en los casos anteriores.

2. Para la identificación "uno a muchos" (one-to-many matching, es decir, la verificación de un vínculo entre la foto de una persona y una base de datos), hubo tasas elevadas de falsos positivos respecto de mujeres afroamericanas, y el estudio señala que estos diferenciales son importantes, en tanto podrían llevar a falsas acusaciones.

20 La información de estas pruebas también puede encontrarse en https://www.nist.gov/news-events/news/2018/11/nist-evaluation-shows-advanceface-recognition-softwares-capabilities (Recuperado el 24/12/2021)

${ }^{21}$ La información, más el informe completo del NIST, puede ser consultado aquí: https://www.nist.gov/news-events/news/2019/12/nist-study-evaluates-effects-raceage-sex-face-recognition-software (Recuperado el 24/12/2021) 
No obstante, el informe concluye diciendo que no todos los algoritmos arrojan estas altas tasas de falsos positivos: "los algoritmos diferentes se desempeñan de manera diferente".

En vista de estos resultados tan dispares, ya comienza a vislumbrarse un proceso de marcha atrás en algunos casos. En Estados Unidos, y pese a la creciente utilización del reconocimiento facial por distintas fuerzas de seguridad en todo el país, algunas ciudades han determinado prohibiciones. Las ciudades de Oakland y San Francisco ya han bloqueado la aplicación del sistema por parte de sus fuerzas policiales. Esto ocurrió antes de que los legisladores estatales de California, a raíz de los resultados de la prueba realizada por la ACLU, aprobaran una ley prohibiendo temporalmente la utilización de este sistema en el territorio del estado, hasta 2023. Sin embargo, esta prohibición solo aplica a las cámaras corporales utilizadas por la policía, lo que permite que el reconocimiento facial pueda ser utilizado a través de cámaras estáticas. Asimismo, las fuerzas federales de seguridad no están alcanzadas por esta normativa (CNN Business, 2019).

Dentro de toda esta incertidumbre generada por los resultados variamente contrapuestos entre las distintas evaluaciones del sistema, hay un aspecto positivo que conviene resaltar, y que es significativo: lenta pero paulatinamente se están esbozando objeciones a la aplicación del reconocimiento facial, que parece realizarse sin detenerse a pensar lo suficiente en los peligros que ello conlleva. Cabría esperarse que esta toma de conciencia solamente tenderá a crecer en estos próximos años y, de esta manera, el reconocimiento facial quedará en la mira de un escrutinio permanente y sostenido por parte de la sociedad.

\section{e. Principio de proporcionalidad en acción}

Tras haber reseñado los tres elementos en pugna, utilicemos ahora las categorías del examen de proporcionalidad para el desarrollo de un análisis en abstracto. No debemos olvidar que el 
resultado es provisorio, en tanto la brevedad y la ausencia de consideración de un caso con elementos concretos evitan que se pueda hacer un escrutinio exhaustivo y preciso de esta cuestión.

Recordemos brevemente: el examen de proporcionalidad está dividido en tres submandatos: idoneidad, necesidad y proporcionalidad en sentido estricto. Respecto de cada una, podemos hacer estas observaciones:

1. Respecto de la idoneidad, lo primero que puede señalarse es que la utilización de la tecnología de reconocimiento facial tiene la capacidad para cumplir con los objetivos de seguridad pública que plantea el Estado y, en ese sentido, habría una cierta adecuación entre el medio (la norma) y la finalidad propuesta (seguridad pública). Eso no quita que un Estado pueda utilizarlo con fines abiertamente ilegítimos, como ilustra el caso de China. Sin embargo, al menos en la generalidad de países que son respetuosos de los derechos humanos y las garantías, es un punto que puede ser admisible, aunque ello dependerá del control judicial en cada país.

2. En cuanto a la necesidad, se puede argumentar que, pese a ser una herramienta idónea, la tecnología de reconocimiento facial no constituye el medio menos lesivo para cumplir con su cometido. Como tuvimos oportunidad de constatar, el reconocimiento facial no está exento de deficiencias. Ahora bien, las técnicas actuales de reconocimiento policial también tienen sus falencias y cuestionamientos. Quizás no podamos hablar con propiedad de dos medios idóneos. Pero, si analizamos uno y otro sistema, y tomamos en cuenta lo que aquí se ha desarrollado sobre la tecnología de reconocimiento facial, podremos apreciar que esta es menos idónea que el statu quo actual. Por dicho motivo, 
y como reseñamos anteriormente, el escrutinio de la ciudadanía sobre la acción estatal en lo relativo a la utilización de esta tecnología debe ser más intenso que nunca.

3. Por último, en lo relativo a la proporcionalidad en sentido estricto, podemos resaltar lo siguiente:

i. Respecto a la seguridad pública, que es el interés que el Estado desea proteger, puede haber discrepancias según cada sociedad, pero se puede coincidir en que su importancia puede oscilar entre moderada y grave, en la medida en que su cumplimiento hace posible la vida convivida de todos los ciudadanos dentro de la comunidad.

ii. Pero respecto de la presunción de inocencia y del derecho a la igualdad y no discriminación, que son los principios que se ven afectados en estos casos, se encuentran dentro del catálogo de derechos fundamentales que el Estado debe proteger. Más aún, las deficiencias que hemos reseñado respecto de la utilización de la tecnología de reconocimiento facial ponen de manifiesto que, pese a la importancia que ostentan, estos derechos son vulnerados. Por dicho motivo, el nivel de afectación de estos principios es manifiestamente grave.

iii. Como corolario, podemos observar que la importancia de la seguridad pública no justifica las afectaciones que el reconocimiento facial realiza respecto de los dos derechos aquí analizados, y con más razón si consideramos que en algunos lugares se avanza con su 
implementación pese a los peligros y problemas detectados.

\section{Conclusión}

A raíz de todo lo expresado en los acápites anteriores, no sorprende que el uso de esta tecnología haya sido prohibido, aunque sea solo de forma parcial, y aunque haya sido solo en lugares aislados. En el balance, está empezando a pesar cada vez más la debida consideración de las vulneraciones a las garantías individuales, vulneraciones que, una vez ocurridas, son irremediables, y que pueden abrir una puerta que después va a ser muy difícil cerrar.

Sin embargo, estamos todavía a tiempo de replantearnos seriamente si realmente queremos que el reconocimiento facial, aún con las ventajas que puede traer en determinadas áreas, tenga un rol prominente en nuestra sociedad. A lo largo de este artículo, hemos intentado adentrarnos un poco más en los problemas que su aplicación en la esfera "pública" supone. Si, al final del día, en los distintos países se deseara seguir usando esta tecnología, será necesario que haya salvaguardas más intensas. De lo contrario, esto terminará escapando a nuestro control y generará muchos más problemas de los que ya existen.

\section{Referencias}

ACLU. (2018). “Amazon's Face Recognition Falsely Matched 28 Members of Congress With Mugshots". Recuperado de https://www.aclu.org/blog/privacy-technology/surveillancetechnologies/amazons-face-recognition-falsely-matched-28 $(24 / 12 / 2021)$.

ACLU of Northern California. (2019). "Facial Recognition Technology Falsely Identifies 26 California Legislators with Mugshots". Recuperado de https://www.aclunc.org/news/facial- 
recognition-technology-falsely-identifies-26-californialegislators-mugshots $(24 / 12 / 2021)$

Alexy, R. (1993). Teoría de los derechos fundamentales (Ernesto Garzón Valdés, trad.). Centro de Estudios Constitucionales. (Obra original publicada en 1986). Recuperado de http://www.pensamientopenal.com.ar/system/files/2014/12/d octrina37294.pdf (24/12/2021)

Alexy, R. (2008). “La fórmula del peso”. En Carbonell, M. (Ed.), El principio de proporcionalidad y la interpretación constitucional. Ministerio de Justicia y Derechos Humanos. Recuperado de https://biblioteca.cejamericas.org/bitstream/handle/2015/1914 16PPIC.pdf?sequence $=1$ \&isAllowed $=y(24 / 12 / 2021)$

BBC News Mundo. (2019). "La polémica en China por la imposición del reconocimiento facial a todos los compradores de teléfonos". Recuperado de https://www.bbc.com/mundo/noticias-50622301 (24/12/2021)

BBC News Mundo. (2018). "China y los Uigures: los campos ocultos de reeducación donde internan a los musulmanes en la nación asiática". Recuperado de https://www.bbc.com/mundo/noticias-internacional-46073663 $(24 / 12 / 2021)$

Clarín. (2019). “Cuántos detenidos hubo con el sistema de reconocimiento facial en 60 días". Recuperado de https://www.clarin.com/policiales/detenidos-sistemareconocimiento-facial-60-dias_0_XVMAqEeul.html $(24 / 12 / 2021)$

CNN Business. (2019). “California lawmakers ban facial-recognition software from police body cams". Recuperado de https://edition.cnn.com/2019/09/12/tech/california-bodycam-facial-recognition-ban/index.html (24/12/2021)

Coccoli, J. (2017). "The Challenges of New Technologies in the Implementation of Human Rights: an Analysis of Some Critical Issues in the Digital Era", Peace Human Rights Governance, 1(2), 223-250. Recuperado de http://phrg.padovauniversitypress.it/system/files/papers/2017 _2_4.pdf $(24 / 12 / 2021)$ 
Galetta, A. (2013) 'The changing nature of the presumption of innocence in today's surveillance societies: rewrite human rights or regulate the use of surveillance technologies?' European Journal of Law and Technology, Vol. 4, No. 2. Recuperado de https://ejlt.org/index.php/ejlt/article/view/221/377 $(24 / 12 / 2021)$

Feldstein, S. (2019). The Global Expansion of AI Surveillance, Carnegie Endowment for International Peace. Recuperado de https://carnegieendowment.org/files/WP-FeldsteinAISurveillance final1.pdf $(24 / 12 / 2021)$

Ferreyra, E. (2020). "El ojo blindado. Una perspectiva de derechos fundamentales sobre el uso de tecnología de reconocimiento facial por parte de fuerzas de seguridad". En Riquert, M. (dir.) Sueiro, C. (coord.), Derecho penal e informática, volumen 3, Hammurabi.

Garvie, C., Bedoya, A.M, Frankle, J. (Eds.) (2016). The Perpetual LineUp. Unregulated Police Face Recognition In America, Center on Privacy \& Technology. Recuperado de https://www.perpetuallineup.org/sites/default/files/201612/The\%20Perpetual\%20Line-Up\%20\%20Center\%20on\%20Privacy\%20and\%20Technology\%20at\%20 Georgetown\%20Law\%20-\%20121616.pdf (24/12/2021).

Pato, J.N., Millett, L.I. (Eds.) (2010), Biometric Recognition: Challenges and Opportunities, National Academies Press.

Klatt, M. \& Meister, M. (2012). The Constitutional Structure of Proportionality, Oxford University Press. ISBN: 9780199662463. DOI: 10.1093/acprof:oso/9780199662463.001.0001

Legarre, S. (2004). Poder de policía y moralidad pública. Fundamentos y aplicaciones. Editorial Ábaco.

Mann, M., Smith, M. (2017), “Automatic Facial Recognition Technology: Recent Developments and Approaches to Oversight", University of New South Wales Law Journal, volumen 40, número 1, pp. 121-145. Recuperado de https://www.unswlawjournal.unsw.edu.au/wpcontent/uploads/2017/09/40-1-11.pdf (24/12/2021). 
Villaverde, I. (2008). "La resolución de conflictos entre derechos fundamentales. El principio de proporcionalidad". En Carbonell, M. (Ed.), El principio de proporcionalidad y la interpretación constitucional. Ministerio de Justicia y Derechos Humanos. Recuperado de https://biblioteca.cejamericas.org/bitstream/handle/2015/1914 16PPIC.pdf?sequence=1\&isAllowed=y $(24 / 12 / 2021)$ 